\title{
Assessment of effect of treatments on WBCs count variations in diabetic-hcv patients treated with three different regimens of hepatitis
}

\begin{abstract}
Purpose: The objective of the study was to assess the effect of different three HCV regmin therapies.

Methodology: The reterospective cross sectional study was carried out in KPK Pakistan the total 450 sample size was taken and data was collected with the help of questionnaire .

Results: The mean WBCs count and variations in 94,38 , and 17 diabetic-HCV patients respectively. The WBCs0, WBCs3, WBCs6 represent the white blood cells counts which were noted periodically before initiation the therapy, 3months after the therapy and 6 months after the therapy. The mean WBCs count of 94 patients who consumed IFN + RBV is 6.66 which dropped to 5 and then elevated to 5.42 .Similarly the WBCs count dropped from 7.06 to 5.6 in first three months and then increased to 6.1 at the 6 th months in patients who consumed Peg-ifn+RBV
\end{abstract}

Conclusion: Infected population received anti-HCV therapies INF+RIB and PEGINF+RIB during hepatitis $C$ treatment showed a uniform reduction in mean white blood cells count, $\mathrm{SOF}+\mathrm{RBV}$ showed a lower reduction in WBCs count.
Volume 2 Issue 6 - 2018

\author{
Muhammad Khalid Khan,' Haroon Khan,' \\ Fazul ur Rehman,' Barkat Ali Khan,' Altaf Ali \\ Mangi,' Awais Ahmed Juno,2 Nadeem Lund, ${ }^{3}$ \\ Waseem Abbas Malhani ${ }^{3}$

\section{'Faculty of Pharmacy, Gomal University, Pakistan} \\ 2Ministry of Health, Drug Regulatory Authority, Pakistan \\ ${ }^{3}$ Department of Pharmacy, Shaheed Mohtarma Benazir Bhutto \\ Medical University, Pakistan
}

\section{Correspondence: Altaf Ali Mangi, Faculty of Pharmacy, Gomal University, Pakistan, Tel +92 3313421263,}

Emailaltafa4I@yahoo.com

Received: July 28, 2018 | Published: December 26, 2018

Keywords: hepatitis, therapy, WBC count

\section{Introduction}

Hepatitis is commonly known as inflammation of liver and is combination of two words i.e. "Hepar" a Greek word meaning liver and "Ititis" It is a Latin word meaning inflammation. There are different types of hepatitis Non-viral hepatitis, ${ }^{1,2}$ Hepatitis commonly referred to as inflammation of hepatic parenchymal cells and are associated with both infectious agent like viruses as well as triggered by noninfectious agents. ${ }^{3,4}$ The non-infectious causes of hepatitis includes heavy intake of alcohol, nonalcoholic fatty liver disease, metabolic disorder, drugs and autoimmune disease. there are different types of hepatitis like Alcoholic hepatitis In most part of the world alcoholic consumption is high and is associated with higher risk of development of liver disease compared to nonalcoholic Rehm et al. ${ }^{5,6}$ Approximately, $20 \%$ of the peoples develop hepatitis secondary to chronic alcohol abuse mostly between the age of 40-60 years. Furthermore, prolong intake of alcohol is associated with severe hepatic dysfunction, fibrosis and cirrhosis. Genetic factors may predispose the patient to alcohol abuse and with resultant hepatitis. The risk of development alcoholic hepatitis is higher in female alcoholic abusers compared to male adductors Donato et al. ${ }^{7}$ Drug-Induced hepatitis the liver is a major site for the metabolism of numerous drugs, however, certain drugs are associated with development of sign and symptoms of hepatitis similar to viral hepatitis. The onset of hepatitis symptoms can appear any time after the initiation of drug therapy. ${ }^{8}$ Mostly, the sign and symptoms of hepatitis disappear when the drug is withdrawn, but in some cases they may progress to serious liver disease. A drug most commonly implicated in liver dysfunction includes isoniazid (INH), methyldopa, phenytoin, valporic acid, and the sulfonamide drugs. Very high doses of acetaminophen (Paracetamol) have been reported by numerous studies to be associated severe liver damage and even death, especially when used with alcohol Larson et al. ${ }^{12}$ Viral hepatitis Hepatitis caused by virus is called viral hepatitis. Most cases of hepatitis are caused by viruses that infect liver cells and begin multiplying. ${ }^{9}$ there are five different types of virus that causes hepatitis. These are HAV, HBV, HDV, HEV and HCV. Successive milestone was achieved in the field of chemotherapy after the development of interferon and antiviral agents to treat HCV. The first and the most important drug that are using on a very large is interferon against chronic hepatitis C. It is used alone and in combination with other drugs like Ribavirin. Peg-interferon alpha- $2^{\mathrm{a}}$ and alpha- $2^{\mathrm{b}}$, is a long acting interferon used widely against hepatitis virus. ${ }^{10,11}$ Ribavirin is a nucleoside analogue with known antiviral activity against both RNA and DNA viruses. ${ }^{12}$

\section{Methodology}

\section{Study design}

The study was retrospective, comparative and cross-sectional. This study mainly focused on the success rate of different treatments combinations in diabetic $\mathrm{HCV}$ patients by comparing treatment outcomes.

\section{Study area, participants and samples}

This retrospective study was held in Bannu and Lakki Marwat districts of Khyber Pakhtunkhwa and participants from these two districts were included in the study. The total sample size was 450 collected from Districts of KPK Pakistan A questionnaire form was designed and validated with help of a statistician before starting 
the survey, which was used for data collection and input of clinical profile from the records of four public and private sector hospitals and laboratories Table $1 \& 2$.

Table I Prevalence of diabetes mellitus in HCV patients

\begin{tabular}{lll}
\hline Study sites & $\begin{array}{l}\text { Studied } \\
\text { population }\end{array}$ & Diabetic population \\
\hline DHQ hospital Bannu & 250 & $83(33.2 \%)$ \\
KGN hospital Bannu & 40 & $22(55 \%)$ \\
DHQ hospital Lakki & 150 & $39(26 \%)$ \\
City hospital Lakki & 11 & $5(45 \%)$ \\
Total & 450 & $149(33.1 \%)$ \\
\hline
\end{tabular}

Table 2 Gender distribution in HCV and diabetic-HCV populations

$$
\text { Gender HCV patients Diabetic HCV }
$$

Male $\quad 209(69 \%) \quad 115(77 \%)$

Female $\quad 81(31 \%)$

Total $\quad 300(100 \%) \quad 149(100 \%)$

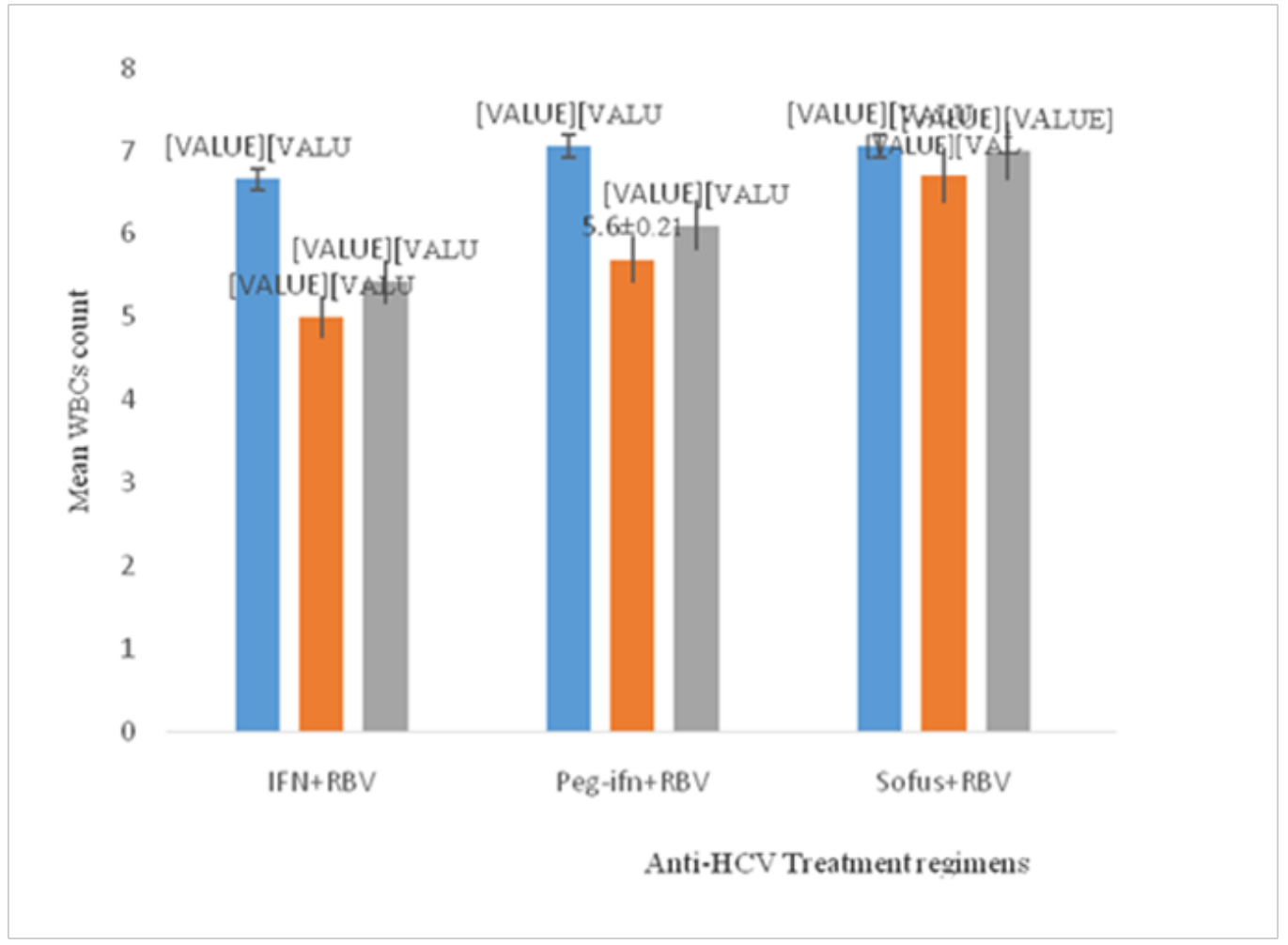

Figure I WBCs count variations in diabetic-HCV patients at month 3 and 6 of different anti-HCV treatment regimens ( $\mathrm{n}=149$ ).

The results in the Figure 1 shows the mean WBCs values of diabetic-HCV patients who consumed the above three combinations of anti-HCV therapies. During hepatitis-C therapy the WBCs value are decreased in first two to 8 weeks of the therapy. Clinically significant decrease occurred in WBCs count at 3 months of using treatments, and then there was increase in WBCs count at the end of 6 months of treatment as at this stage the body immune system creates more no. of WBCs to combat the infection. The Figure 1 shows the mean WBCs count and variations in 94, 38, and 17 diabetic-HCV patients respectively. The WBCs0, WBCs3, WBCs6 represent the white blood cells counts which were noted periodically before initiation the therapy, 3 months after the therapy and 6 months after the therapy. The mean WBCs count of 94 patients who consumed IFN+RBV is 6.66 which dropped to 5 and then elevated to 5.42.Similarly the WBCs count dropped from 7.06 to 5.6 in first three months and then increased to 6.1 at the $6^{\text {th }}$ months in patients who consumed Peg-ifn+RBV. The Figure 3.4 shows that there is transient decrease in WBCs count in case of SOF+RBV combination. The WBCs count dropped from 7.06 to 6.7 and then increased to 7.2. All the mean values are presented in multiple of $1000 .(1 \times 1000)$.

\section{Discussion}

In our present study all the $\mathrm{HCV}$ infected population received anti-HCV therapies INF+RIB and PEG-INF+RIB during hepatitis $\mathrm{C}$ treatment showed a uniform reduction in mean white blood cells count, $\mathrm{SOF}+\mathrm{RBV}$ showed a lower reduction in WBCs count because neutropenia is the side effect of interferon and peg-interferon. In our 
study, WBCs count in IFN+RBV combination therapy decreased from mean 6.6 Mcl to 5.42 Mcl, 7.6 to 6.1 Mcl in PEG-IFN+RBV and 7.06 to $7.2 \mathrm{Mcl}$ in $\mathrm{SOF}+\mathrm{RBV}$. Several studies favor our finding, According to white blood cells count reduced up to $30-40 \%$ during interferon based therapy. Similarly reported that $10-20 \%$ reduction occurred in leucocytes count during hepatitis C therapy. Dusheiko in 2010 also reported that there was a transient decrease in WBCs count treated with interferon or peg-interferon therapy. It is essential to monitor and control earlier for the presence of diabetes mellitus type II and also rule out hepatitis $\mathrm{C}$ virus infection among diabetic populations. Therefore patients who are HCV positive and have advanced age are recommended for blood glucose test and presence of diabetes mellitus if they are showing poor response or no response to the anti-viral therapy. Improvement of insulin resistance before initiating interferon therapy favors a good response to interferon therapy. HCV patients may avoid weight gain by changing life style (Hypo-caloric diet/ exercise), usage of insulin sensitizers, in the form of Metformin, to diminish hepatic gluconeogenesis, and pioglitazone to sensitize insulin receptors and mobilize visceral fat to subcutaneous tissues. According to the results of our study the specific population $(\mathrm{HCV}+\mathrm{DM})$ need specific care and intentions to get maximum outcomes of the therapy.

\section{Acknowledgments}

None

\section{Conflicts of interest}

The author declares that there is no conflict of interest.

\section{References}

1. Alaei M, Negro F. Hepatitis C Virus and Glucose and Lipid Metabolism. Diabetes Metab. 2008;3(4):692-700.

2. Al Ashgar H, Khan MQ, Helmy A, et al. Sustained Virologic Response to Peg interferon A-2a and Ribavirin in 335 Patients with Chronic Hepatitis C: A Tertiary Care Center Experience. Saudi J Gastroenterol. 2008;14(2):58-65.
3. Albertoni G, Girao MJ, Schor N. Mini Review: Current Molecular Methods for the Detection and Quantification of Hepatitis B Virus, Hepatitis C Virus, and Human Immunodeficiency Virus Type 1. Int J Infect Dis. 2014;2(5):145-149.

4. Alborino F, Burighel A, Tiller FW, et al. Multicentre Evaluation of a Fully Automated Third-Generation Anti-HCV Antibody Screening Test with Excellent Sensitivity and Specificity. Med Microbiol Immunol. 2011;200(2):77-83.

5. Allison ME, Wreghitt T, Palmer CR, et al. Evidence for a Link between Hepatitis C Virus Infection and Diabetes Mellitus in a Cirrhotic Population. J Hepatol. 1994;2(1):1135-1139.

6. Alter MJ, Kuhnert WL, Finelli L, et al. Guidelines For Laboratory Testing and Result Reporting of Antibody to Hepatitis C Virus. Massachusetts Medical Society. 2003;52:1-13.

7. Angulo P. Global Epidemiology: Non-alcoholic Fatty Liver Disease. Aliment Pharmacol Ther. 2007;2(5):883-889.

8. Anwar MI, Rahman M, Hassan MU, et al. Prevalence of Active Hepatitis C Virus Infections among General Public of Lahore, Pakistan. Virol J. $2013 ; 10: 351$.

9. Attaullah SK, Ali I. Hepatitis C Virus Genotypes in Pakistan: A Systemic Review. Virol J. 2011;8:433.

10. Kumada H, Toyota J, Okanoue T, et al. Telaprevir with Peginterferon and Ribavirin for Treatment-Naive Patients Chronically Infected with HCV of Genotype 1 in Japan. J Hepatol. 2012;5(6):78-84

11. Kurosaki M, Tanaka Y, Nishida N, et al. Pre-Treatment Prediction of Response to Pegylated-Interferon Plus Ribavirin for Chronic Hepatitis C Using Genetic Polymorphism in I128b and Viral Factors. J Hepatol. 2011;5(4):439-448.

12. Larson AM, Polson J, Fontana RJ, et al. Acetaminophen $\square$ Induced Acute Liver Failure: Results of a United States Multi-centre, Prospective Study. Hepatol. 2005;4(2):1364-1372. 